

Empresas, recursos económicos y gobiernos indigenas: una aproximación al estudio de las redes clientelares en un resguardo indigena en la Altillanura colombiana ${ }^{1}$

Laura Calle Alzate ${ }^{2}$

Universidad Complutense de Madrid, España ${ }^{3}$

lcalle@ucm.es

Recibido: 22 de julio de 2016

Aceptado: 15 de febrero de 2017

Disponible en línea: 14 de diciembre de 2017

\footnotetext{
1 Artículo de reflexión.

2 Ph.D. en Antropología, Universidad Complutense de Madrid (España).

3 Profesora Asociada.
} 


\title{
Empresas, recursos económicos y gobiernos indigenas: una aproximación al estudio de las redes clientelares en un resguardo indigena en la Altillanura colombiana
}

\begin{abstract}
Resumen
A partir de los datos construidos como resultado de mi trabajo de campo etnográfico en el Resguardo Wacoyo, este artículo pretende ilustrar algunos de los efectos de la presencia de empresas nacionales e internacionales, dedicadas a la extracción de materias primas y la agroindustria, sobre las relaciones politicas internas del Resguardo. La presencia de estas empresas ha tenido impactos significativos en las dinámicas políticas internas de los pueblos indigenas asentados en el municipio, debilitando y fragmentando a las comunidades y sus gobiernos. En particular, argumentaré que estos recursos se han convertido en la nueva base económica que alimenta las redes clientelares comunitarias indígenas, y en la causa de tensiones y disputas políticas entre líderes y comuneros indígenas. Empezaré por describir cómo se impuso un nuevo modelo de desarrollo en la región, para luego explicar el funcionamiento de las redes clientelares a nivel regional y comunitario.

Palabras clave: sikuani; Altillanura; clientelismo; modelo extractivo-exportador; pueblos indígenas

\section{Businesses, Economic Resources, and Indigenous Governments: An Approach to the Study of Clientelistic Networks in an Indigenous Reserve of the Colombian High Plain}

\begin{abstract}
This paper intends to illustrate some of the effects that derive from the presence of national and international companies engaged in the extraction of raw materials and agroindustry work on the internal political relationships of an indigenous territory, based on the results of the ethnographic fieldwork conducted in the Wacoyo reserve. The presence of these companies has had significant impacts on the internal political dynamics of indigenous peoples living in the municipality, weakening and fragmenting communities and their governments. Particularly, this paper exposes how these resources have become the new economic base that feeds clientelistic networks in indigenous communities, and how it causes political tension and disputes between indigenous comuneros and leaders. It begins by describing how a new development model was imposed in the region, and later explains how clientelistic networks work in regions and communities.
\end{abstract}

Keywords: Sikuani; high plain; clientelism; extractive-export model; indigenous people

\section{Empresas, recursos económicos e governos indigenas: aproximação para o estudo de redes clientelares em um resguardo indigena na Altillanura colombiana}

\section{Resumo}

A partir dos dados construídos como resultado do meu trabalho de campo etnográfico no Resguardo Wacoyo, esta comunicação visa ilustrar alguns efeitos da presença de empresas nacionais e internacionais, dedicadas à extração de matérias-primas e agroindústria, sobre as relações políticas internas do Resguardo. A presença destas empresas tiveram impactos significativos nas dinâmicas politicas internas dos povos indígenas que habitam no munícipio, enfraquecendo e fragmentando as comunidades e os seus governos. Em particular, vou argumentar que esses recursos tornaram-se a nova base económica que alimenta as redes de clientelismo comunitárias indigenas; e na causa de tensões e conflitos políticos entre líderes e comuneiros indígenas. Vou começar a descrever como foi que um novo modelo de desenvolvimento na região foi imposto para passar a explicar o funcionamento das redes de clientelismo no nível regional e comunitário.

Palavras-chave: sikuani; altillanura; clientelismo; modelo extrativo-exportador; povos indígenas 
Históricamente, el pueblo sikuani ha habitado la Orinoquía colombo-venezolana. Los primeros antropólogos que arribaron a la región, a mediados del siglo XX, los describió como bandas de cazadores recolectores seminómadas que practicaban una horticultura incipiente (Reichel-Dolmatoff, 1944; Wilbert, 1957; Morey, 1970; Morey y Metzger, 1974). Actualmente, el pueblo sikuani vive en resguardos, ${ }^{4}$ que a su vez están divididos en comunidades. ${ }^{5}$ Wacoyo $^{6}$ es uno de los nueve resguardos indígenas ubicados en el municipio de Puerto Gaitán, ${ }^{7}$ en la Orinoquía colombiana. La mayor parte de sus habitantes se autodefinen como pertenecientes al pueblo sikuani o jiwi. ${ }^{8}$ Este pueblo no ha sido ajeno a diversos procesos de colonización y usurpación territorial, como tampoco al exterminio físico y cultural. La Orinoquía, concebida como una región de "frontera" (Gómez, 1991), se ha transformado en el tiempo, pues tradicionalmente ha sido un polo de atracción de población foránea debido a las diferentes olas de colonización causadas por las cualidades del territorio, rico en materias primas, que ha llevado al desarrollo de economías de tipo extractivo, como la extracción del caucho, la cacería, la explotación petrolera, la ganadería y, finalmente, el narcotráfico. Además, por sus grandes extensiones de tierra, su ubicación estratégica y su potencialidad económica, la Orinoquía es un territorio atractivo para el ingreso de multinacionales y macroproyectos agroindustriales, como por ejemplo los cultivos de palma aceitera o de pino, característicos también de la economía de tipo extractiva propia de la zona. Las políticas estatales que entregaron en concesión los territorios considerados "baldíos" estimularon la inmigración hacia esta región (Calle Alzate, 2010). Por lo tanto, durante las últimas dos décadas los habitantes de Wacoyo han

4 Según la Constitución de 1991, los resguardos son una institución legal y sociopolítica de carácter especial, conformada por una o más comunidades indígenas, que con un título de propiedad colectiva gozan de las garantías de la propiedad privada, poseen su territorio y se rigen para el manejo de este y su vida interna por una organización autónoma amparada por el fuero indígena y su sistema normativo propio (véase el Artículo 21 del Decreto 2164 de 1995).

5 Las comunidades son asentamientos indígenas conformados generalmente por una o varias familias extensas.

6 En algunos mapas y documentos oficiales, el Resguardo Wacoyo aparece registrado como "Comunidades de Corocito, Yopalito y Walabó". Wacoyo fue legalizado por el Instituto Colombiano de Reforma Agraria (Incora) en el año de 1993. Tiene una extensión territorial de 8.050 hectáreas y queda ubicado a 20 kilómetros, aproximadamente, del casco urbano de Puerto Gaitán.

7 El Municipio de Puerto Gaitán se encuentra ubicado en el Departamento del Meta, a 281 kilómetros de Bogotá, la capital de la República.

8 Durante mi trabajo de campo en enero de 2016, un grupo de sabedores sikuani plantearon que querían cambiar la autodenominación de 'sikuani' por la de 'jiwi', que en su lengua significa 'gente'. 
tenido que sobrevivir a la presión de las economías de enclave que imperan en la región, y a otros fenómenos como la presencia de grupos armados ilegales, principalmente grupos paramilitares.

Desde el año 2001, el Gobierno nacional ha venido implementando el proyecto de convertir la Altillanura ${ }^{9}$ en un polo de desarro1lo agrícola, petrolero y minero. Esto último ha ocasionado cambios drásticos en la tenencia, uso y cobertura del suelo, así como la llegada de empresarios de otras partes del país, lo que ha transformado el ordenamiento social y productivo de la región (La Rota-Aguilera y Salcedo, 2016). Muchas de estas empresas se han ubicado en las inmediaciones de los resguardos indígenas, lo que ha generado que sus actividades se superpongan al territorio de las comunidades.

Según lo relatado por los sikuani, los altos salarios traídos por las petroleras han "roto por completo con lo poco que quedaba de su economía comunitaria" sikuani. Así me lo explicó una comunera indígena del Resguardo Wacoyo:

[...] Antes todo el mundo tenía su cultivo de yuca. Y si yo hoy hacía casabe, ${ }^{10}$ mañana hacías tú, pero después ya no. Antes todos comían de todo. Si traían cazería acá, todos comíamos; si traían mi papa allá, todos comíamos; si traía Pepito allá, todos comíamos, y así. Eso era como una cadena. Pero hoy en día ya no [...] Eso cambió, porque de un momento a otro todo es comprar, comprar y comprar. Yo no sé, ahora hay que pagar por todo. Nosotros mantenemos esa colaboración acá con mi hermana, pero porque somos vecinas. Y eso sí en casi todas las culturas pues se colabora con el vecino, que un plátano, que la cebolla; porque el familiar de uno es el vecino, pero ya con la otra gente no. Ni vienen, ni uno va. Ayer a mí me dieron un pedazo de carne, pero porque mi marido les prestó la moto para ir por el bicho. Si no, no nos hubieran dado nada. Ya aquí eso se perdió. Todas las mañanas uno se enteraba de que era lo que pasaba ayer, todos se enteraban lo que iba a pasar hoy. Pero ahora nadie sabe lo

9 La Altillanura abarca 13’557.956,35 hectáreas. Se abre paso desde el municipio de Puerto López, pasa por la margen derecha del río Meta y llega hasta la desembocadura del río Orinoco en el Departamento del Vichada. Esta región comprende los municipios de Puerto Gaitán, Puerto López, La Primavera, Puerto Carreño y Santa Rosalía.

${ }^{10}$ Pan elaborado a partir de la yuca. 
que pasa en ningún lado. En todas las comunidades es igual y eso es culpa de la petrolera. La gente gana plata y ya no produce su propio alimento. Ellos ahora tienen la billetera gordita para la cervecita, pero el día de mañana se les acabó el contrato y se quedan sin nada. Yo por eso ahora hago mi casabe y cobro por cada torta. Ahora todo es plata, aquí ya es como vivir en el pueblo. Ya no se hace trabajo comunitario, ya no hay unuma, aquí todo es plata. Acá la cultura ya se perdió [...]. (Entrevista a comunera indígena, 2013, marzo 2)

Según el relato de esta comunera, con la llegada del dinero de la petrolera la comunidad se quebrantó y solo permanecen los lazos de reciprocidad entre la familia más cercana - gran parte de las relaciones entre los comuneros se limitan a intercambios monetarios-; además, compara la vida en la comunidad con la del pueblo. Varias familias han dejado de sembrar y de producir su propia comida, y han pasado a comprarla en el pueblo con lo que ganan como asalariados. Como veremos, estos recursos no solo han cambiado las relaciones de reciprocidad comunitarias.

A partir de los datos construidos como resultado de mi trabajo de campo etnográfico, realizado entre diciembre de 2012 y marzo de 2013 y posteriormente en febrero de 2016 en el Resguardo, ${ }^{11}$ este artículo pretende ilustrar uno los efectos de la presencia de empresas nacionales e internacionales dedicadas a la extracción de materias primas y la agroindustria sobre las relaciones politicas internas del Resguardo Wacoyo. En el transcurso de mi investigación he analizado que la presencia de estas empresas ha influido en las dinámicas politicas internas de los pueblos indígenas asentados en el municipio, pero, sobre todo, que los recursos económicos de las empresas privadas se han convertido en la nueva base económica que alimenta las redes clientelares comunitarias indigenas, y en la causa de tensiones y disputas políticas entre líderes y comuneros indigenas. Empezaré por describir cómo se impone un modelo de desarrollo diferente en la región, para luego explicar el funcionamiento de las redes clientelares a nivel regional y comunitario.

11 Esta estancia etnográfica pertenece a parte de la investigación que realicé para la elaboración de mi tesis doctoral. En estos periodos hice observación participante combinada con entrevistas semiestructuradas, conversaciones informales, relatos de vida y revisión de archivos. 


\section{Tierra a la vista: la imposición de un modelo de desarrollo diferente}

Desde principios del siglo XX, las compañías petroleras extranjeras que operan en Colombia declararon la Orinoquía como "zona de reserva" a través de la obtención de grandes extensiones de terreno por medio de concesiones que el Estado les hizo (y les sigue haciendo). En los años cincuenta empezó la exploración petrolera en la región y, desde 1976, empresas nacionales y extranjeras han extraído petróleo en el Departamento del Meta, el cual se ubica en la actualidad entre los tres mayores productores del país. Desde entonces los sikuani han tenido contacto con las empresas. La intelectual y lideresa sikuani Rosalba Jiménez Amaya relata que el cacique Ramón Gaitán, quien era el jefe de un caserío en San Pedro de Arimena conocido como Matanegra, trabajó como guía de la petrolera Trocco, compañia que abrió la carretera hasta Puerto Carreño (Jiménez, 1991/2010). Esto fue confirmado por algunos abuelos sikuani que me relataron que, en aquel entonces, algunas empresas contrataban a indígenas como "baquianos". ${ }^{12}$ No obstante, la explotación petrolera no ha sido el principal sistema económico en la región, como sí lo ha sido la ganadería extensiva, la cual se afianzó durante el siglo XX y ha sido una de las principales causas de la usurpación de tierras y del exterminio de los pueblos indígenas de la Orinoquía, entre ellos el pueblo sikuani (Gómez, 1991).

Durante la década del noventa se comenzó a percibir un cambio de modelo, pues se empezaron a implementar métodos experimentales para mejorar los suelos de la Altillanura para regular su acidez. Esto suscitó un interés considerable en el sector empresarial, pues las tierras adquirieron un potencial productivo mucho más alto (La Rota-Aguilera y Salcedo, 2016). El Gobierno de Álvaro Uribe Vélez revivió la fantasía del presidente Belisario Betancur de convertir la Orinoquía, en general, y la Altillanura, en particular, en el nuevo polo de desarrollo del país. Para ello impulsó la iniciativa "Renacimiento de la Orinoquía", cuyo proyecto bandera era el desarrollo de más de seis millones de hectáreas en cultivos

12 En los Llanos Orientales se les denomina 'baquianos' a aquellas personas que conocen muy bien la región y que trabajan como guías. 
agroindustriales, principalmente forestales, de caucho y de palma de aceite. ${ }^{13}$ El proyecto de Uribe Vélez empató con las "Locomotoras de Desarrollo" ${ }^{14}$ del Gobierno del presidente Juan Manuel Santos, en el cual se fijó como prioridad, desde 2010, el desarrollo no solo de infraestructura, sino también de oferta de tierras en esta región (Presidencia de la República de Colombia, 2011; Domínguez, 2013).

Por lo anterior, se puso en marcha una nueva oleada de colonización hacia los Llanos Orientales, que ha generado un cambio demográfico significativo en la región. En este contexto, se crearon leyes que se ajustaban a esta nueva configuración territorial. Tal vez la más importante fue el Estatuto de Desarrollo Rural de 2006, pues a través de este se legalizaron millones de hectáreas de tierras que los paramilitares habían despojado (Rodríguez González, 2014).

Por otra parte, y de manera casi simultánea, aumentaron los descubrimientos de pozos petroleros. Durante mi primer trabajo de campo en $2004,{ }^{15}$ en las proximidades al Resguardo tenían presencia las empresas Meta Petroleum Corporation, ${ }^{16}$ subsidiaria de la empresa Pacific Rubiales Energy, y el grupo petrogasífero estadounidense Hupecol. Para entonces, el yacimiento de Rubiales tenía una producción de 5.500 barriles diarios, razón por la cual tendía a convertirse en un próspero campo petrolífero (Calle Alzate, 2005). Siete años más tarde, a finales de agosto de 2012, además de las seis empresas que realizaban actividades de explotación petrolera, se encontraban otras 17 en etapa de exploración. ${ }^{17}$ Este panorama

${ }^{13}$ El Gobierno de Álvaro Uribe incluso le presentó este proyecto al Gobierno de Japón por su potencial de captura de carbono, bajo el Mecanismo de Desarrollo Limpio del Protocolo de Kyoto, pero esta negociación nunca prosperó. Entre los argumentos que se usaron para el impulso de este megaproyecto en la Orinoquía estaba su supuesto beneficio ambiental, pues sabanas improductivas y desprovistas de valor ambiental (por su falta de árboles) se convertirían en bosques o cultivos perennes con mayor stock de carbono.

${ }^{14}$ El Plan Nacional de Desarrollo propuesto por el Gobierno de Juan Manuel Santos tiene como eje cinco locomotoras: infraestructura, vivienda, agro, minería e innovación.

${ }^{15}$ El trabajo de campo etnográfico del año 2004 hizo parte de la investigación que realicé para mi tesina del pregrado en Antropología

${ }^{16}$ Las directivas de la empresa Metapetroleum Corporation aspiraban a incrementar la producción de petróleo de 5.500 barriles diarios a 10.000 barriles para el 2005, y tenían una proyección de 20.000 barriles diarios para cinco años después.

17 “[...] Reportes económicos estiman que la producción de hidrocarburos en el Meta durante 2012 cerró en diciembre con un promedio diario de 469.160 barriles, esto es, un incremento del 9,4\% respecto al mismo periodo del año anterior. Esos indicadores demuestran que el Meta es el principal productor de crudo del país, con una participación del 49\% en la producción nacional” (Massé \& Camargo Castro, 2013, pp. 7-8) 
ha repercutido en un incremento significativo de los precios de la tierra en la región de los Llanos Orientales (Molano, 2012; Espitia, 2013; Massé y Camargo Castro, 2013).

En los inicios de 2013, casi la totalidad del territorio del Departamento del Meta había sido concedida para la exploración petrolera a un total de veintiún empresas de Colombia, Canadá, Brasil, China, Corea y la India, ${ }^{18}$ y allí se estaba produciendo alrededor del 55\% del petróleo nacional (Massé y Camargo Castro, 2013). En esta región del país se concentró el desarrollo de los crudos pesados, uno de los ejes de la estrategia para aumentar la producción y reservas de petróleo. Colombia, el cuarto mayor productor de crudo de Latinoamérica, tiene unas reservas de petróleo de 2.000 millones de barriles, y algunas de estas se encuentran en el subsuelo de los territorios de los pueblos indígenas.

No obstante lo anterior, con la bajada del precio del petróleo a partir de 2010, la situación ha cambiado de manera trascendente y los proyectos agroindustriales se han priorizado. A los municipios cubiertos por el Consejo Nacional de Política Económica y Social (Conpes) ${ }^{19}$ se les asignan recursos con miras a reorganizar el territorio e imponer el modelo de desarrollo agroindustrial y seguir fomentando tanto al sector minero como al ganadero. Esta tendencia responde a las cifras presentadas por el Departamento Nacional de Planeación (DNP), que calcula que unos 3,5 millones de hectáreas

18 Tecpetrol Colombia SAS (empresa de origen argentino); Petronova (empresa canadiense); Montecz S.A. (empresa colombiana); SK Innovation (empresa surcoreana); Petrobras Colombia Limited (empresa de origen brasilero); Hupecol Operating Co LLC (empresa de origen estadounidense); ONGC Videsh LTD., sucursal colombiana (empresa de origen indio); Winchester Oil and Gas (empresa colombiana adquirida por la norteamericana GeoPark); Pluspetrol Colombia Corporation (empresa canadiense); Maurel and Prom Colombia B.V (empresa de origen francés); Columbus Energy (empresa de origen canadiense); Grupo C\&C Energía Barbados Sucursal Colombia (de origen barbadense, filial de Pacific Rubiales Energy); Canacol Energy (empresa canadiense); Consorcio Andes Energía Argentina S.A.; Integra Oil \& Gas S.A.S (empresa argentina); Emerald Energy PLC Sucursal Colombia (empresa de origen chino, hace parte de la corporación Sinochem); BC Exploración y Producción (empresa española); Meta Petroleum Corp. (subsidiaria de la canadiense Pacific Rubiales Energy); Ecopetrol S.A.; Hocol S.A. (empresa colombiana, filial de Ecopetrol); Petrominerales Colombia LTD., sucursal Colombia (empresa de origen canadiense); New Granada Energy Corporation (empresa de origen chino).

19 El Consejo Nacional de Política Económica y Social es el máximo organismo de coordinación de la política económica en Colombia. No dicta decretos, sino que da las directrices y la orientación de la política macro. El Conpes está presidido por el primer mandatario del país y la secretaría técnica la ejerce el jefe del Departamento Nacional de Planeación, quien elabora los documentos a ser tratados en cada una de las sesiones. 
de la Altillanura tienen potencial productivo para el desarrollo agrícola y forestal (La Rota-Aguilera y Salcedo, 2016).

En la Altillanura existen 58 resguardos indígenas pertenecientes a 12 pueblos diferentes; el Resguardo Wacoyo ${ }^{20}$ es uno de ellos. Los proyectos de desarrollo no tienen en cuenta esta condición poblacional, que data de épocas precolombinas, ni el hecho de que más del 30\% del territorio de la región está constituido bajo la figura de resguardo. Se desconoce además que la violencia armada, la dinámica minero-energética y el boom agroindustrial están produciendo graves impactos para la población indígena.

La participación indígena en el diseño de las políticas de desarrollo es escasa y, por lo tanto, la consulta previa es una "promesa ilusoria", en palabras de Villa (2011), o desde mi punto de vista, una puesta en escena o teatro (Calle Alzate, 2014). Esto se evidencia en la invisibilización del punto de vista indígena en los documentos emitidos por el Conpes y el DNP, que definieron la Orinoquía como un territorio abierto a la exploración y a la colonización, lleno de oportunidades para la iniciativa privada, en donde, a diferencia de la Amazonía, no existen mayores restricciones ambientales (Departamento Nacional de Planeación, 2014). ${ }^{21}$

\section{Clientelismo y el gobierno indigena en el Resguardo Wacoyo}

En este apartado me interesa abordar la concepción antropológica y cultural del "clientelismo" y las "redes clientelares" propuesta por autores como Auyero (2002), Duston (2005) y Tosoni (2007). Desde

\footnotetext{
${ }^{20}$ Las tierras de resguardo dentro del municipio de Puerto Gaitán tienen un área de 883.000 hectáreas, las cuales se encuentran al suroriente de la zona donde termina la sabana y empieza la selva, y están subdivididas en nueve resguardos. Para efectos administrativos, la organización Unuma divide el territorio en tres zonas: la zona Selva, que comprende los resguardos del sur, ubicados en las cabeceras del río Uva y entre el río Tillabá y el Teviare, incluyendo los resguardos de El Tigre y Alto Unuma; la zona Planas, que comprende los resguardos de Awaliba, Vencedor Piriri, Domo Planas, Walianae, Iwiwi; y la zona Meta, que comprende los resguardos de Corosal Tapaojo y el Resguardo Wacoyo.

${ }^{21}$ El Plan de Desarrollo 2006-2010 “Estado Comunitario Desarrollo para Todos”, elaborado durante el Gobierno de Álvaro Uribe Vélez, planteó que la Orinoquía hacía parte de las regiones de Colombia en fase de formación, al tiempo que la considera como un territorio abierto a la exploración y a la colonización, lleno de oportunidades para la iniciativa privada, en donde, a diferencia de la Amazonía, no existen mayores restricciones ambientales.
} 
esta perspectiva, las "redes clientelares" son una forma de sociabilidad en la que se involucran tres actores: "patrón", "mediador" y "cliente", y en la que personas con diferentes grados de autoridad se encuentran ligadas mediante lazos de amistad, parentesco, afinidad e interés. Esta forma supera la interpretación clásica del clientelismo, que lo entiende como una relación de dominación diádica y vertical en la que un individuo de estatus socioeconómico más alto (el patrón) usa su influencia y recursos para ofrecer protección y beneficios a la persona de estatus más bajo (cliente), quien a su vez le retribuye al patrón ofreciéndole apoyo, asistencia y servicios personales (Powell, 1970; Kaufman, 1974; Farinetti, 1998). Desde la perspectiva antropológica, el análisis del clientelismo como una relación diádica (patrón/cliente) no permite ver las conexiones políticas, sociales, económicas y culturales entre los patrones y su clientela, y deja de lado el rol central que juegan los mediadores o brokers, el tráfico de influencias que estos ejercitan con aquellos que controlan los bienes y servicios y su posición con los clientes. El "clientelismo", entonces, no es un fenómeno homogéneo ni limitado, sino un fenómeno social que produce y requiere de redes para su configuración. Aquí hablo de redes clientelares comunitarias para resaltar especialmente el papel del líder indígena como mediador en la red clientelar y la injerencia que esto tiene en las relaciones políticas en las comunidades indígenas sikuani del Resguardo Wacoyo.

Según mi análisis, el gobierno sikuani del Resguardo Wacoyo está consolidado en cuatro niveles: el familiar, el comunitario, el regional y el nacional. Una red de familias conforma una comunidad, esa comunidad tiene una autoridad visible, que es el Capitán. Luego, el conjunto de capitanes de todas las comunidades conforma lo que se conoce como el Consejo de Capitanes. Este último elige a un Gobernador general del Resguardo o Capitán Mayor, quien debe ser aprobado formalmente en una asamblea conformada por los habitantes del Resguardo. El Capitán Mayor es el representante legal del Resguardo y del pueblo, y su periodo de gobierno dura un año. Como autoridad, representa a su pueblo a nivel regional ante 
la Asociación de Autoridades Indígenas Tradicionales (Unuma), ${ }^{22}$ que reúne algunos de los resguardos de Puerto Gaitán, en tanto que a nivel nacional lo hace ante la Organización Nacional Indígena de Colombia (ONIC).

Formalmente, los capitanes tienen una doble funcionalidad: a nivel interno, son quienes orientan, controlan y acompañan a los miembros de la comunidad, y quienes velan por la cohesión familiar y por el bienestar general; a nivel externo, su función es coordinar acciones con las instancias representativas, como las instituciones estatales, las ONG, los grupos religiosos, las organizaciones indígenas, entre otros. Gran parte de estas acciones están ligadas a la presentación de proyectos y la gestión de recursos para invertir en el Resguardo.

Auyero (1998) señala que los intercambios clientelares no son el resultado de un cálculo racional, sino una elección práctica aprendida a través del tiempo y experimentada en la vida cotidiana de los actores. Desde mi punto de vista, esta interpretación, aunque pensada en otro contexto, nos ayuda a entender la manera en que se ha transformado la organización política sikuani, y cómo los intercambios clientelares se han convertido en parte fundamental de la cultura politica de este pueblo.

Como describí al inicio del texto, para algunos sikuani la economía comunitaria está quebrantada. Esta economía se basaba en dos prácticas que los habitantes de Wacoyo definen como "tradicionales": el unuma, o trabajo comunitario, y el wakena, que se refiere a la repartición de una presa de cacería entre los miembros de la comunidad, o socialización de los alimentos. Ambas actividades se definían a partir de las jerarquías comunitarias de género,

\footnotetext{
${ }^{22}$ Si el pueblo indígena lo desea, puede afiliar su resguardo y sus respectivas autoridades tradicionales a una Organización Indígena Regional o a una Asociación de Cabildos o de Autoridades Indígenas, y estas, a su vez, se afilian a una Organización Indígena de carácter nacional. Hasta finales del 2012 los nueve resguardos de Puerto Gaitán y sus respectivos cabildos o consejos de capitanes pertenecían a la organización Unuma, que desde los años noventa se organizó a partir de una junta directiva que se elige cada cuatro años. A su vez, Unuma está afiliada a la ONIC y hace parte del grupo de organizaciones que conforman la Macro-Orinoquía. Sin embargo, en la actualidad se han conformado tres asociaciones indígenas más: la Asociación de Cabildos Indígenas del Departamento del Meta (ACIM-Unuma), la Asociación de Autoridades Tradicionales Indígenas (Penamata Kaitorrobiwi) y la Asociación de Autoridades Tradicionales Indígenas Unuma, a la que Wacoyo pertenece hoy en día.
} 
edad y parentesco, eran importantes para la cohesión comunitaria y representaban una fuente de legitimación del poder del capitán como cabeza de la comunidad. Además de la comida, los sikuani solian redistribuir otro tipo de bienes y recursos, principalmente mercancías manufacturadas que obtenían a través del trueque con los "blancos" o como parte del salario para aquellos que trabajaban como peones en los hatos ganaderos (Calle Alzate, 2015). Sin embargo, el flujo de bienes y mercancías cambia a partir de las décadas del setenta y ochenta.

Durante estos años, los líderes indígenas empezaron a recibir recursos económicos de proyectos financiados principalmente por las ONG nacionales e internacionales y algunas instituciones estatales, como el Instituto Colombiano de Reforma Agraria (Incora) y el Instituto Colombiano de Bienestar Familiar (ICBF) (Calle Alzate, 2015). Esto coincidió con la emergencia de la Organización Indígena Unuma y la burocratización de las autoridades indígenas, lo que dio lugar a la conformación de una élite política. Esta última creó estrategias para estabilizar su gobernabilidad, dentro de la cuales estaba la creación de redes clientelares en el entorno comunitario. La redistribución de los recursos que entraron en las comunidades durante la década del ochenta, en vez de regirse por las jerarquías comunitarias de género y generación, como ocurría con el wakena, se hizo a través de la creación de nuevas alianzas y de relaciones de tipo clientelar. Esto, para que la nueva élite sikuani pudiera mantener su posición de autoridad y para salvaguardar el control en el acceso a los recursos. Por lo tanto, los líderes pasan a tener el monopolio de los recursos y a hacer un uso privado de estos. Así mismo, las jerarquías de género, generación y parentesco que determinaban la redistribución anterior comienzan a coincidir con una nueva manera de redistribución de recursos ligada a las redes clientelares.

Luego, a partir de la década de los noventa, con la vinculación de los resguardos indígenas al Sistema General de Participación, más conocido como ley de transferencias, la función de los líderes como gestores de proyectos se institucionaliza; una de sus 
responsabilidades es canalizar los recursos, bienes y servicios que empiezan a llegar hacia el espacio de la comunidad. Esto terminó por afianzar un sistema de redistribución de recursos ligado a la creación de redes clientelares comunitarias.

Como explicaré más adelante, los comuneros y líderes sikuani no llaman clientelismo ni a la canalización de los recursos de las empresas por parte de los líderes y capitanes, ni a la distribución de estos recursos a cambio de lealtades políticas. Los sikuani tienden a identificar las prácticas clientelistas con "la política" y "los políticos". Veremos, por lo tanto, que la "gestión de proyectos" o la "gestión de recursos" son entendidas como una práctica propia de "los políticos", y que el acto como tal se define como "hacer politica". Por otra parte, los líderes definen la redistribución de los recursos obtenidos entre la clientela como "ayuda" o "colaboración", mientras que los comuneros en ocasiones la definen como "favor" o "derecho". Los sikuani también llaman "hacer política" a la compraventa de votos, que asocian, por lo general, a la política municipal en época electoral, y está ligada principalmente a la política de los "blancos".

En este caso, no me detendré en analizar lo que ocurrió en la década del ochenta o la problemática de las transferencias y su incidencia en las redes clientelares, sino en cómo la imposición de un nuevo modelo de desarrollo en la Altillanura, la presencia de empresas y los recursos que llegan con ellas funcionan como base económica de las redes clientelares regionales y comunales, incidiendo fuertemente en las formas de gobierno de los sikuani y la manera en que los líderes ejercen "la política".

\section{Redes clientelares: plano regional y comunal}

Según un estudio realizado por el Grupo Semillas (2012), en la Altillanura existen decenas de megaproyectos agroindustriales, forestales y del sector minero-energético. Los habitantes de Wacoyo mantienen relaciones con varias de estas empresas, pero las más 
cercanas y con más tensiones son definitivamente aquellas que colindan con los límites del Resguardo. Este es el caso de la Fazenda del grupo Aliar S.A., Cepsa o Cepcol S.A. en su operación en Colombia y Mavalle.

Las economías de enclave, caracterizadas por su carácter extractivo, sustentado en la concentración de la actividad productiva y de la mano de obra, tienen grandes impactos sobre el entorno de las poblaciones aledañas. Es especialmente determinante cómo las economías basadas en el petróleo, las plantaciones agroforestales o la actividad agroindustrial derivan en la llegada de dinero de una forma nunca antes vista (La Rota-Aguilera y Salcedo, 2016), entablando relaciones activas o pasivas con la población circundante. Ya sea a través de empleos para los habitantes del Resguardo, proyectos de inversión ligados a sus políticas de responsabilidad social corporativa, la financiación de procesos de consulta previa o inversiones voluntarias, que se conocen con el nombre de IVS (Inversión Social Voluntaria), hay una serie de recursos que potencialmente pueden ser invertidos en los resguardos.

Las redes clientelares se refuerzan en el momento en el que los líderes indígenas ven en las empresas una fuente de financiación alternativa al Estado para costear y ejecutar proyectos en sus comunidades. En este contexto, las redes se constituyen en dos planos: el regional y el comunal.

En el plano regional, el líder indígena es el mediador y funciona como una pieza de anclaje entre el patrón (empresa) y el cliente (comuneros indígenas), pues es el que crea el contacto y distribuye los recursos otorgados por el patrón. En el plano comunal, en cambio, el capitán ocupa la posición de patrón y los patriarcas de cada una de las unidades familiares pasan a ocupar el papel de mediadores; el resto de los comuneros mantienen su posición de clientes.

Los sikuani de Wacoyo han tramitado proyectos de diversa índole ante las empresas. Dentro de estos se encuentran proyectos para el mejoramiento de vivienda, seguridad alimentaria, solicitud 
de becas universitarias y de grados técnicos para los jóvenes del Resguardo, así como solicitud de construcción de obras de infraestructura y centros de salud, entre otros. La gestión de estos proyectos está determinada por las relaciones que los habitantes del Resguardo tienen con las empresas, por lo general volubles, pues se mueven entre el conflicto, la negociación y el acuerdo, además de estar determinadas por una clara asimetría de poder.

Durante mi trabajo de campo registré que la gestión de recursos por parte de los líderes indígenas hacia las empresas se puede dar en varios contextos, como por ejemplo en los procesos de consulta previa y durante conflictos directos con las empresas. No obstante, la gestión de recursos no solo responde a contextos circunstanciales, sino que hace parte de la cotidianidad de los líderes y está relacionada con lo que los sikuani definen como "hacer política". En este caso, me limitaré a exponer lo que ocurre cuando un líder presenta de manera voluntaria un proyecto financiable ante el representante de la empresa y lo que ocurre cuando gestiona empleos en la empresa para los habitantes del Resguardo, y la manera en que esto influye en la red clientelar.

\section{Presentación de proyectos y obtención de recursos}

Con respecto a este contexto en particular, la labor del líder consiste en redactar un proyecto y dirigirse al representante social de la empresa para solicitar su posible financiación. Para los líderes sikuani, esta primera etapa es denominada como "la gestión del recurso" y definida como parte fundamental del quehacer del lider, y por lo tanto del "hacer política". El gobierno de Wacoyo ha presentado ante varias empresas el proyecto para el financiamiento de la elaboración del Plan de Vida Sikuani del Resguardo. Durante mi estancia en el Resguardo, una comisión de líderes encargados del desarrollo del apartado de territorio del Plan de Vida mantuvo reuniones con la representante social de una de las empresas 
agroindustriales con la que colinda el Resguardo para acordar esta financiación. Esta gestión se hizo en nombre de todo el Resguardo, pero también hay proyectos más pequeños que se solicitan a nivel comunitario.

Por lo tanto, la gestión de los recursos no la hace únicamente el Capitán Mayor o Gobernador del Resguardo, sino que cada uno de los líderes intenta gestionar proyectos de manera bilateral para beneficiar a su propia comunidad y también para mantener a su clientela, y, con ello, su estabilidad politica. De esta manera, desde la perspectiva sikuani, no solo los capitanes o los miembros del gobierno están habilitados para "hacer política", sino que lo puede hacer cualquier líder con la capacidad de gestionar proyectos y recursos para el Resguardo, las comunidades o las familias.

Desde mi perspectiva, el líder indígena, como mediador, es el que crea el contacto y distribuye los recursos otorgados por el patrón y, por lo tanto, el anclaje entre el patrón y el cliente (Auyero, 2001). Además, canaliza los recursos, bienes y servicios que empiezan a llegar a las comunidades, es decir, es quien "hace política". Por lo tanto, tenemos a la empresa como patrón; múltiples mediadores, que son los líderes indígenas, y los comuneros como clientes.

Los líderes gestionan los recursos que benefician a un sector de la población, pero no a los comuneros en conjunto. Las lealtades de parentesco juegan un papel primordial en este caso, pues gran parte de la clientela hace parte de la familia extensa del líder. Esto es importante porque indica que la redistribución definida por las jerarquías comunitarias de género, generación y parentesco coexiste con la de las redes clientelares, y se influyen mutuamente. Por ejemplo, un día un líder indígena me comentó que, aunque el Capitán Mayor era elegido por votación en la asamblea, nunca ganaba el más adecuado para gobernar, sino el que tenía más familia, porque toda la familia votaba por él (Registro Diario de Campo, 2016, enero). Por lo tanto, el clientelismo comunal no es un simple intercambio de favores por lealtades politicas, sino que implica además un conjunto de relaciones personales y familiares con 
elementos de afecto y reciprocidad difusa, que operan como una extensión de las redes de ayuda mutua (Durston, 2005).

Algunos líderes sikuani definen la distribución de recursos en el entorno familiar como "ayuda" o "colaboración", y la perciben en términos de obligación moral. De la misma manera, defienden este tipo de prácticas, que también califican de "compadrazgo" o "vecinazgo", con frases como "yo le ayudé a él primero porque es mi vecino" o "entre vecinos nos colaboramos" y "cómo no le voy a ayudar primero a mi vecino". Algunos capitanes justifican la existencia de la red clientelar, que funciona casi como una comunidad imaginada en torno a la reciprocidad, la redistribución y la cooperación comunitaria. Por lo tanto, los líderes sikuani denominan la red clientelar como "comunidad" o "familia", y la definen como una comunidad cohesionada que desde mi interpretación responde a una idealización del "deber ser".

Los capitanes y líderes indígenas son ordenadores del gasto. No existe una regulación legal dentro del resguardo y esto les permite decidir, según sus propios criterios, cómo se gastan los recursos que obtienen de su gestión ante las empresas. La regulación viene de los comuneros indígenas y de los demás líderes, quienes cuestionan constantemente el uso de esos dineros. Esto significa que la manera de "hacer política" o las relaciones clientelistas tienen legitimidad entre los sikuani, pero también que los comuneros y comuneras como clientes no son enteramente pasivos, ya que la negociación de sus lealtades políticas incluye contraprestaciones permanentes.

La relación clientelar debe estar basada en la responsabilidad mutua. La lealtad, el prestigio y el honor acumulados por el mediador, en este caso el líder indígena, deben ser recompensados con la distribución de recursos y servicios. En la mayoría de los casos, los comuneros (clientes) tienen vías de comunicación entre sí, y una falla en la asistencia a un cliente disminuye la confianza de todos. De esta manera, en Wacoyo nos encontramos con múltiples escenarios marcados por la sospecha o desconfianza hacia los líderes y 
capitanes, que en ocasiones se ven sometidos a procesos de rendición de cuentas. El chisme, por ejemplo, es un mecanismo de control social efectivo. Si un comunero acusa a un líder de incumplir el contrato clientelar, este puede ser castigado. Como la relación es estructuralmente de corto a mediano plazo, el líder indígena tiene que demostrar un gran cuidado en mantener su reputación como una persona que se preocupa por los problemas y necesidades de los comuneros (Günes-Ayata, 1997).

Los procesos de rendición de cuentas se generan, por lo general, cuando un sector de la comunidad considera que los recursos no se distribuyeron de la manera adecuada, por lo que sugiero que para los sikuani el problema en Wacoyo no es que las petroleras o las agroindustrias estén en el territorio, sino quién se beneficia y cómo se reparten los recursos que estas empresas traen.

Los procesos de negociación entre los líderes indígenas y las empresas, ya sean petroleras o agroindustrias, son percibidos por gran parte de la población, incluidos los líderes, como transacciones. También hay una noción generalizada entre la élite política indígena de que sin dinero no se puede gobernar. A pesar de que para los sikuani el uso del dinero no es propio de su cultura, algunos líderes indígenas son conscientes de que dependen de él, pero además afirman que los recursos económicos son necesarios para la gestión y para la existencia misma del gobierno indígena.

Como sugieren Chaves y Hoyos (2011), la gobernabilidad de los gobiernos indígenas pasa a depender entonces de su capacidad para movilizar los recursos hacia sus grupos de interés: al interior de la comunidad, para mantener su autoridad, y fuera de ella, para establecer y reforzar redes con proveedores de materiales para los contratos, clave para seguir usufructuando los recursos. Por esto, los procesos de negociación con las empresas en ocasiones han puesto en jaque la autoridad de algunos líderes (Calle Alzate, 2014). 


\section{Jóvenes indigenas: entre la mediación y la clientela}

Como expliqué, la redacción de proyectos se ha vuelto fundamental en el quehacer político de los sikuani de Wacoyo. Muchos líderes indígenas no tienen los conocimientos técnicos para cumplir con las exigencias administrativas que tiene el trámite de un proyecto ante las empresas. Por lo tanto, es necesario establecer alianzas estratégicas. Los líderes necesitan de un técnico que haga los proyectos para así garantizar los recursos. Por lo tanto, algunos jóvenes han buscado capacitarse en la redacción y formulación de proyectos. Los líderes adultos que no tienen conocimientos de informática los apadrinan como secretarios para que estos realicen las tareas técnicas. Estos líderes jóvenes, por lo general, son varones, a pesar de que hay muchas jovencitas sikuani que también han terminado su bachillerato y tienen conocimientos técnicos.

Los jóvenes líderes, además de asistir al líder principal (patrón), cumplen el papel de mediadores en la red clientelar. En ocasiones hacen de intermediarios entre los comuneros y el capitán, organizando apoyo político y distribuyendo recursos. Esto ha generado que un grupo de jóvenes indígenas escolarizados, principalmente varones, se estén vinculando al gobierno indígena. Por otra parte, tanto las empresas como la administración municipal priorizan la participación de jóvenes indígenas que cuentan con formación técnica, al haber sido escolarizados en el sistema educativo nacional, y manejan un lenguaje común con los mestizos. Por lo tanto, en algunas comunidades, los capitanes mayores han sido gradualmente reemplazados por capitanes más jóvenes que oscilan entre los 20 y los 30 años. Por ejemplo, el Capitán Mayor elegido para 2014 y 2015 es un líder joven. Sin embargo, no debemos perder de vista que las jerarquías de género y edad siguen teniendo mucho peso dentro de la sociedad sikuani, por lo que en gran medida el líder joven precisa del apoyo político de los mayores para no ser desbancado. Esto permite la emergencia de otro mediador, el patriarca, y la permanencia de muchos otros jóvenes como clientes. 
Muchos de los jóvenes indígenas vieron en las petroleras una oportunidad de ascender socialmente. Un joven sikuani me explicó que su sueño era trabajar en la petrolera, porque de esa forma iba a poder comprarse una moto, ponerle electricidad a la casa y comprar un televisor con señal satelital para poder ver los partidos del Real Madrid (Registro Diario de Campo, 2013, febrero 5). Durante mi trabajo de campo, observé la desocupación de muchos de los jóvenes varones de la comunidad. Algunos tenían expectativas de ingresar a la universidad, para estudiar una carrera, o al Servicio Nacional de Aprendizaje (SENA), para hacer algún grado técnico. Otros esperaban que les saliera un contrato en alguna de las empresas que hacen presencia en la región. Aunque la participación de los jóvenes varones en las actividades comunitarias varía de acuerdo con cada comunidad, en varios de los caseríos del Resguardo hay un desinterés generalizado de los jóvenes hacia estas.

Según los líderes sikuani, cuando los jóvenes terminan su escolarización se sienten desarraigados, porque han perdido un sentido de pertenencia hacia su propia cultura. Su manera de pensar no corresponde a la cosmovisión que sus generaciones anteriores sí comparten, por lo que hay un desinterés hacia la vida comunitaria y muchos ven en las petroleras una salida a su evidente estado de anomia.

Así, hay un sector del gobierno indígena que aboga por "el retorno a las costumbres", mientras que otro sector solicita capacitación y becas para que los jóvenes indígenas se vinculen al mundo laboral y a la economía de mercado. Sin embargo, no todos los jóvenes tienen las mismas oportunidades para trabajar en las empresas de la zona y es aquí donde entran a jugar las dinámicas de las relaciones políticas comunitarias. La posibilidad de que un joven entre a trabajar allí está determinada tanto por las jerarquías internas como por el clientelismo comunal. Las élites políticas indígenas, como representantes del pueblo ante las empresas privadas, han monopolizado los puestos de trabajo en las petroleras y empresas agroindustriales para engrosar su clientela y mantener su estabilidad politica. 
En el entorno comunal, los líderes pasan de mediadores a patrones al monopolizar los puestos de trabajo ofrecidos por la petrolera. Los comuneros que quieren acceder a estos puestos ofrecen su lealtad y apoyo político a cambio de la gestión ante la petrolera. En esta red clientelar, la relación no solo se da entre el líder y el sujeto beneficiado, sino también con toda su familia. Es decir, el joven no es el único que debe lealtad y apoyo político al líder que gestionó su empleo, sino que su familia también participa de ese contrato informal. Esto ocurre porque cuando un joven sikuani se convierte en obrero, sus ingresos son mucho mayores que los de cualquier otro joven de la comunidad o de cualquier otro miembro de su familia. Como resultado, no solo él asciende socialmente, sino también su familia entera al beneficiarse de esos recursos, entrando así a formar parte de la clientela del líder.

Como la familia está involucrada, generalmente la negociación no se da entre el joven que va a trabajar y el líder, sino entre este último y el patriarca de la familia. Por lo tanto, en la red clientelar comunal el patriarca ejerce de mediador entre el líder indígena y su hijo, sobrino o nieto. Es aquí donde se vislumbran las jerarquías de edad. Las jerarquias de género también se hacen visibles, pues las familias prefieren que en la empresa trabaje un hijo varón. Esto se da por dos razones: una es que los obreros de la petrolera deben ausentarse durante varios dias de la comunidad y, en el caso de las mujeres, se considera que están abandonados el hogar y los hijos. Otra es que las ofertas de empleo del sector generalmente buscan jóvenes varones. El hecho de que no todas las familias pueden tener a uno de sus miembros trabajando para la petrolera ha generado una división interna a nivel comunitario.

Con el tiempo, los jóvenes que salen a trabajar a las empresas ya no quieren regresar al Resguardo, porque experimentan una nueva forma de vida y ven en esta una oportunidad de camuflarse entre los mestizos del pueblo y de escapar del racismo estructural al que han estado sometidos. Consecuentemente, muchos de ellos se han desligado de la comunidad y de muchos de los valores culturales sikuani, proceso que además se ha acelerado con la llegada de internet y la 
televisión satelital. Algunos mayores sikuani hablan de una inminente pérdida de la cultura. Así lo expresó uno de los líderes de la comunidad, quien me explicó que entre los más adultos también hay una desconexión con el pueblo, su cultura y el territorio. En sus palabras:

[...] Entonces, por ejemplo, si un viejo tiene dos hijos que trabajan en la petrolera, pues ya no trabaja más porque si cada hijo se saca de salario un millón quinientos, tres millones mensuales. Ese ya es un indígena rico. En ese momento al indígena se le olvida que necesita el Resguardo, que necesita el territorio, ya deja de sembrar la yuca, porque le están pagando. Entonces con esa plata compra el arroz para su familia y su casa. El casabe y el pescado también lo compra. Pero cuando se acaba el chicharrón también es grave. Ahí sí se acuerda de su región [...]. (Entrevista a líder sikuani, 2013, enero 19)

Por lo tanto, no solo los jóvenes, sino también los mayores, se sienten desinteresados frente a las dinámicas comunitarias. Por otra parte, como señalé al inicio del artículo, los altos salarios que llegaron con las petroleras han roto por completo con lo poco que quedaba de la economía comunitaria sikuani. Las familias han tenido que adaptarse a estas nuevas circunstancias, por lo que ahora en las comunidades hay un grupo de familias que sigue sembrado yuca y haciendo el casabe y otros que tienen más poder adquisitivo y que lo compran. Así, nos encontramos con un sistema de clasificación al interior del Resguardo que diferencia a las familias "ricas" de las familias "pobres", sustentado en los salarios de aquellos jóvenes que trabajan como obreros en las petroleras.

Esto me recordó la afirmación que hizo un líder una noche que conversábamos, cuando le pregunté si ese año iban a sembrar conuco, a lo que me respondió que la comunidad ahora estaba dividida en "estratos", porque había gente con más poder económico que otra. Me dio a entender que su familia pertenecía a ese grupo y que, por lo tanto, no tenían conuco ni hacian casabe, porque tenían dinero para comprárselo, a diferencia de aquellas familias que sí tenian que prepararlo. 
Con la baja del precio del petróleo a partir de 2010, el desempleo en Puerto Gaitán ha incrementado considerablemente y los jóvenes indigenas que trabajaban en las empresas también se han quedado sin empleo ("Los 'Beverly pobres", 2016). En este contexto, los jóvenes tienen como opción entrar a trabajar como operarios en las fincas agroindustriales, empleo en el que se paga un salario mínimo legal vigente ${ }^{23}$ más el subsidio de transporte, y que generalmente se consigue con la gestión de alguno de los líderes de las comunidades. También suelen buscar becas de formación en el SENA y algunos aspiran a una beca universitaria. En la actualidad hay tres jóvenes del Resguardo cursando estudios universitarios, uno de ellos con una beca que otorgó la empresa petrolera Pacific Rubiales como parte de su inversión social. Otros han hecho cursos en el SENA financiados por el grupo la Fazenda (Registro Diario de Campo, 2016, enero 19). La investigadora Flor Ángela Buitrago Escobar analiza en uno de sus artículos la situación de estos jóvenes sikuani universitarios, y señala por qué el contexto económico y social de la región es clave para comprender qué factores posibilitan la elección de trayectorias de vida para los jóvenes indígenas sikuani. Buitrago describe y analiza cómo se presentan oportunidades viables para estos jóvenes indígenas y cómo estas se logran a través de una red de relaciones entre distintos actores: actores estatales y funcionarios de entidades, actores de la industria, actores indígenas y actores académicos (Buitrago Escobar, 2014). Al mapa presentado por la autora, me gustaría añadir a los líderes mediadores, que en momentos concretos definen las oportunidades de estos jóvenes, quienes cumplen el rol de clientes.

\section{Consideraciones finales}

El líder, que es un sujeto de estatus socioeconómico más alto, usa su influencia y recursos para ofrecer protección y beneficios a otros que no tienen acceso directo a dichos recursos. De esta forma, nos encontramos nuevamente con una relación de doble dependencia: la de los comuneros hacia las élites indígenas, para beneficiarse de los recursos de las

\footnotetext{
$23 \$ 689.454$ pesos colombianos en 2016.
} 
empresas, y la de las élites indígenas hacia los recursos externos, para mantener la estabilidad del gobierno indígena y el equilibrio de las relaciones politicas comunitarias. Esta doble dependencia conecta dos redes clientelares: la que se da a nivel comunal y la que se da a nivel regional.

Las empresas, por su parte, habilitan el trabajo de algunos líderes con los que tienen más afinidad, legitimándolos como mediadores entre la empresa y la comunidad. Esto genera una mayor dependencia de los mediadores con respecto al patrón, pues la gestión de los líderes está determinada por la afinidad que estos tengan con la empresa, especialmente con quien ejerce las funciones de responsable social. Así, la aprobación de los proyectos no solo es cuestión de las capacidades de gestión del líder indígena como tal, sino también de la relación que este mantenga con la empresa, que a fin de cuentas es la que decide qué proyectos se aprueban. En ocasiones, estas relaciones son descritas por los sikuani como relaciones de amistad, al referirse al responsable social de la empresa como "mi amigo". Como sugiere Auyero (2001), el poder del mediador se deriva de su posición en la red, y dicho poder consiste en la monopolización de la información y en la capacidad de obstruir o facilitar el flujo de demandas, favores, bienes y servicios, desde o hacia una comunidad.

Durante mi última visita al Resguardo, en enero de 2016, observé el declive de la economía petrolera y la implantación de numerosos cultivos agroindustriales en sus inmediaciones. Esto último ha venido ocasionando cambios drásticos en la tenencia, uso y cobertura del suelo, así como la llegada de empresarios de otras partes del país, lo que ha transformado el ordenamiento social y productivo de la región. El cambio de un modelo productivo caracterizado por cultivos de ciclo corto y para el sustento familiar, por uno consistente en extensos monocultivos permanentes de propiedad de unos pocos (La Rota-Aguilera y Salcedo, 2016), se hacen evidente en el paisaje. En el trayecto desde Puerto Gaitán hacia al Resguardo Wacoyo, en lo que antes eran sabanas, ahora hay cultivos de maíz y soja (Regristro Diario de Campo, 2016, enero 21). Aunque los indígenas seguían negociando con la multinacional de origen español CEPSA, que para entonces era responsable de la explotación de los 
conjuntos de pozos denominados Caracara y Tiple, gran parte de las negociaciones de esos días se centraron en las agroindustrias aledañas, principalmente con el grupo Aliar.

Muchas de las familias que habitan el Resguardo basan su sustento familiar en la recolección del maíz. En la época de cosecha, después de que pasan las máquinas recolectoras, los dueños de los cultivos dejan que los indígenas entren a "repelar". Según afirmaron los habitantes de Wacoyo, es el único trabajo que ha salido en los últimos meses y muchas familias cuentan con la venta de ese maíz para el sustento familiar. Esto, una vez más, depende de la intermediación de los líderes y de su relación con la empresa.

Como he señalado a lo largo de este artículo, en el clientelismo comunal el líder indígena pasa de mediador a patrón al tener el monopolio de los recursos, y en el caso del repeler del maíz, es el líder quien logra obtener el permiso para que las familias puedan entrar a recoger el maíz. El líder indígena, como mediador, tiene un círculo intimo de seguidores con el que compone su propia red clientelar, ligada mediante lazos de amistad, parentesco, afinidad e interés. De esta forma, el líder que logra gestionar recursos paga con dinero o con puestos de trabajo a una clientela, que a su vez empieza a hacer parte de la élite de turno.

En el clientelismo comunal también hay mediadores. Por lo general, los patriarcas, quienes ya no tenían incidencia politica en el gobierno indígena, pero sí mantenían su autoridad en el entorno familiar, articularon la relación entre su familia extensa y el líder. Por lo tanto, nos encontramos con una relación patrón-mediador-cliente en la que hay un intercambio mutuo caracterizado por el estatus desigual entre los actores y el principio de la reciprocidad. Esto a su vez genera una doble dependencia: la de los comuneros hacia las élites indígenas, para beneficiarse de los recursos que llegan a las comunidades, y la de las élites indígenas hacia los recursos externos, para mantener la estabilidad del gobierno indígena y el equilibrio de las relaciones políticas internas. Las relaciones clientelares se han convertido así en parte de la cultura política sikuani. 


\section{Referencias}

Auyero, J. (1998). Desde el punto de vista del cliente. Repensando el tropo del clientelismo político. Apuntes de investigación del Centro de Estudios en Cultura Politica, 2(3), 55-83.

Auyero, J. (2001). La política de los pobres: las prácticas clientelistas del peronismo. Buenos Aires: Ediciones Manantial.

Auyero, J. (2002). Clientelismo político en Argentina: doble vida y negación colectiva. Perfiles Latinoamericanos, (20), 33-52.

Buitrago Escobar, F. A. (2014). La educación indigena en medio de proyectos propios, exigencias estatales y cambios sociales. Revista Internacional de Organización Educativa y Liderazgo, 1(2), 21-37.

Calle Alzate, L. (2005). Autoridad y Poder entre los Sikuani del Resguardo Wacoyo (Trabajo de grado para optar al título de Antropóloga). Universidad Nacional de Colombia, Facultad de Ciencias Humanas, Departamento de Antropología, Bogotá.

Calle Alzate, L. (2010). Para la erradicación del trabajo infantil en la Orinoquía. En F. Correa (Ed.), Infancia y trabajo infantil indigena en Colombia. Bogotá: Facultad de Ciencias Humanas, Universidad Nacional de Colombia.

Calle Alzate, L. (2014). El espejismo de la autonomía indígena: mirada a la situación de una comunidad en la Orinoquía Colombiana. Anuario de Acción Humanitaria y Derechos Humanos, (12), 71-96.

Calle Alzate, L. (2015). La insaciable búsqueda de El Dorado: procesos hegemónicos y dispositivos de dominación en un pueblo sikuani de la Orinoquía colombiana (Tesis de Doctorado). Universidad Complutense de Madrid, Madrid. Recuperado de http://eprints.ucm.es/37892/1/T37273.pdf

Chaves, M. y Hoyos, J. F. (2011). El estado en las márgenes y las márgenes como estado: transferencias económicas y gobiernos indígenas en Putumayo. En: M. Chaves (Ed.), La multiculturalidad estatalizada: indigenas, 
afrodescendientes y configuraciones de estado (115-134). Bogotá: Instituto Colombiano de Antropología e Historia.

Colombia, P. d. (2011, diciembre 2). "Vamos a convertir la Altillanura en el nuevo polo de desarrollo, en la nueva fuerza agrícola" del pais: Presidente Santos. Recuperado de http://wsp.presidencia.gov.co/Prensa/2011/ Diciembre/Paginas/20111202_06.aspx

Departamento Nacional de Planeación. (2014, enero 12). Documento Conpes 3797: Politica para el Desarrollo Integral de la Orinoquí: Altillanura. Recuperado de http: / / portalterritorial.gov.co/apc-aa-files / 40743db9e8588 852c19cb285e420affe/3797.pdf

Dominguez, J. C. (2013, noviembre 15). Plan de 9,6 billones de pesos para la altillanura. Documento Conpes para la zona reúne seis estrategias y será presentado hoy antes de ser llevado a debate y aprobación por el consejo de ministros. Portafolio. Recuperado de http://www.portafolio.co/economia/ finanzas / plan-billones-pesos-altillanura-89022

Durston, J. (2005). El clientelismo político en el campo chileno (primera parte): la democratización cuestionada. Ciencias Sociales Online, 11(1), 1-30.

Espitia, J. (2013, octubre). La evolución del catastro y el recaudo predial en la Altillanura. Corporación Viva la Ciudadanía. Recuperado de http://viva. org.co/cajavirtual/svc0372/pdfs/Articulo680_372.pdf

Farinetti, M. (1998). Clientelismo y protesta: cuando los clientes se rebelan. Apuntes de Investigación, 2(3), 84-103.

Gómez, A. (1991). Indios, colonos y conflictos: una historia regional de los llanos orientales 1870-1970. Bogotá: Siglo XXI Editores - Pontificia Universidad Javeriana - Instituto Colombiano de Antropología, ICANH.

Grupo Semillas. (2012, febrero 9). Alimento y cultura ancestral en la Altillanura colombiana. Recuperado de https://www.grain.org/es/article/ entries /4468-alimento-y-cultura-ancestral-en-la-altillanura-colombiana 
Günes-Ayata, A. (1977). Clientelismo: premoderno, moderno, posmoderno. En J. Auyero (Ed.), ¿Favores por Votos? Estudios sobre clientelismo politico contemporáneo. Buenos Aires: Losada.

Jiménez, R. (1991/2010). Ramón Gaitán. En F. Queixalós y R. Jiménez (Eds.), Entre Cantos y Llantos: Tradición Oral Sikuani (pp. 172-179). Bogotá: Fundación Etnollano.

Kaufman, R. (1974). The Patron-Client Concept and Macro Politics: Prospects and Problems. Comparative Studies in Society and History, 16(4).

La Rota-Aguilera, M. J. y Salcedo, L. (2016). Parte I. La Altillanura: desafios y posibilidades del Ordenamiento Territorial en la nueva frontera agrícola colombiana. En C. Duarte, Desencuentros Territoriales. Tomo II. Caracterización de los conflictos en las regiones de la Altillanura, Putumayo y Montees de María (pp. 23-158). Bogotá: Instituto Colombiano de Antropología.

Los "Beverly pobres". (2016, marzo 26). Semana. Recuperado de http:// www.semana.com/nacion/articulo/regalias-y-precio-del-petroleo-crisiseconomica-en-municipios / 466554

Massé, F. y Camargo Castro, J. (2013). Actores armados ilegales y sector petrolero del Meta informe monográfico. Bogotá: Observatorio Internacional DDR - Ley de Justicia y Paz.

Molano, A. (2012, diciembre 23). La altillanura en crudo. El Espectador. Recuperado de http:/ / www.elespectador.com/noticias/nacional/altillanuracrudo-articulo-393947

Morey, R. V. (1970). Ecology and culture change among the Colombian Guahibo. (Ph.D. dissertation). Pittsburgh: University of Pittsburgh.

Morey, R. V. y Metzger, D. (1974). The Guahibo: People of the Savanna; Acta Ethnologica et Linguistica. Wien: Series Americana 7.

Powell, J. D. (1970, junio). Peasant Society and Clientelist Politics. American Political Science Review, 64(2), 411-425. 
Reichel-Dolmatoff, G. (1944). La cultura material de los indios Guhibo. Revista del Instituto Etnológico Nacional, 1(1), 437-506.

Rodríguez González, I. (2014). Despojo, baldíos y conflicto armado en Puerto Gaitán y Mapiripán (Meta, Colombia) entre 1980 y 2010. Estudios SocioJurídicos, 16(1), 315-342.

Tosoni, M. M. (2007, enero-junio). Notas sobre el clientelismo político en la ciudad de México. Perfiles Latinoamericanos, (29), 47-69.

Villa Rivera, W. (2011). El movimiento social indigena colombiano: entre autonomía y dependencia. En A. C. Betancur (Ed.), Movimientos indigenas en América Latina: resistencia y nuevos modelos de integración. Dinamarca: IWGIA-Serie Debates.

Wilbert, J. (1957). Notes on Guahibo Kinship and Social Organization. Southwestern Journal of Anthropology, 13(1), 88-98.

\section{Cómo citar este artículo}

Calle Alzate, L. (2017). Empresas, recursos económicos y gobiernos indígenas: una aproximación al estudio de las redes clientelares en un resguardo indigena en la Altillanura colombiana. Universitas Humanistica, 84, 171-199. https://doi.org/10.11144/Javeriana.uh84.ereg 